\title{
Social network analysis in medical education
}

\author{
Rachel Isba, ${ }^{1}$ Katherine Woolf ${ }^{2} \&$ Robert Hanneman ${ }^{3}$
}

CONTENT Humans are fundamentally social beings. The social systems within which we live our lives (families, schools, workplaces, professions, friendship groups) have a significant influence on our health, success and well-being. These groups can be characterised as networks and analysed using social network analysis.

SOCIAL NETWORK ANALYSIS Social network analysis is a mainly quantitative method for analysing how relationships between individuals form and affect those individuals, but also how individual relationships build up into wider social structures that influence outcomes at a group level. Recent increases in computational power have increased the accessibility of social network analysis methods for application to medical education research.

\section{APPLICATION TO MEDICAL EDUCA-} TION Social network analysis has been used to explore team-working, social influences on attitudes and behaviours, the influence of social position on individual success, and the relationship between social cohesion and power. This makes social network analysis theories and methods relevant to understanding the social processes underlying academic performance, workplace learning and policymaking and implementation in medical education contexts.

CONCLUSIONS Social network analysis is underused in medical education, yet it is a method that could yield significant insights that would improve experiences and outcomes for medical trainees and educators, and ultimately for patients.

Medical Education 2017: 51: 81-88

doi: $10.1111 /$ medu. 13152

${ }^{1}$ Education Department, Liverpool School of Tropical Medicine, Liverpool, UK

${ }^{2}$ UCL Medical School, Royal Free Hospital, London, UK

${ }^{3}$ Department of Sociology, University of California, Riverside,

California, USA
Correspondence: Rachel Isba, Education Department, Liverpool School of Tropical Medicine, Pembroke Place, Liverpool L3 5QA, UK. E-mail: isba@doctors.org.uk 


\section{INTRODUCTION}

Humans are fundamentally social beings. We are motivated by a need to belong, which we achieve by forming and maintaining interpersonal attachments. These relationships have significant impacts on our health, success and well-being. ${ }^{1}$ The social systems within which we live our lives (families, schools, workplaces, professions, friendship groups, and so on) can be characterised as networks and analysed using social network analysis. ${ }^{2}$

Social network analysis (SNA) is a method for studying the individual relationships between individuals, or groups of individuals, while simultaneously studying the social context. ${ }^{3}$ The value of SNA as a research approach lies in its ability to examine how individuals are embedded within a social structure and also how social structures emerge from the micro-relationships between individuals. ${ }^{4}$ By visualising and quantifying patterns within networks, such as the overall level of connectivity between network members and the presence or absence of cliques, network analysts can learn how the structural properties of a network can constrain or enable the social behaviour of individuals. ${ }^{5}$ SNA therefore has the major advantage of allowing researchers to measure both individual and socio-cultural influences on educational, psychological, economic and health outcomes.

A relatively popular approach in sociology, economics and public health, ${ }^{6-9}$ SNA remains underused in medical education, despite its huge potential for investigating fundamental questions about, for example, the social influences on individual knowledge and skill acquisition, and the development and influence of cultures within specific educational and clinical settings. In this paper we will explain the ideas underpinning social network analysis by briefly describing its origins, then give examples of work in the wider field, and then move on to how social network ideas and methods have been or could be applied in medical education.

ORIGINS OF SOCIAL NETWORK ANALYSIS

The origins of social network analysis are found in a 1930s girls' boarding school in upstate New York. Jacob Moreno and Helen Jennings mapped the social relationships between the pupils to explore why 14 girls had run away over a 2-week period. ${ }^{10}$ They argued that whether or not a girl ran away was not a function of her individual psychology, but of the relationships that she had with the other girls (and whether or not those girls had run away). Although their proposal - that an individual's behaviour depends on, and is influenced by, the behaviour of those around them - seems obvious, Moreno's breakthrough was to create a method to measure social relationships and use them to understand and systematically predict behaviour in a scientific way.

\section{INDIVIDUALS AND RELATIONSHIPS}

Despite the obvious importance of social relationships to individual outcomes in medical and social science research, usually research data are analysed in terms of individuals rather than in terms of relationships. For example, in a drug trial the analysis is at the level of the individual in that it is assumed that each participant's outcome is unrelated to, or statistically independent of, all other participants' outcomes. SNA, by contrast, takes a relational rather than an individual approach. The unit of analysis in SNA is typically the link (tie) between two members (nodes) of a network, collectively called a dyad.

Adding relational factors to individual factors significantly increases our understanding of behaviour in real life, which is so often enacted in a social context. For example, a social network analysis of the predictors of smoking behaviour of 1716 adolescents in 11 British schools examined the influence of gender, age, socio-economic status and parental smoking behaviour on students' smoking behaviour over time, but also looked at the friendships (or absence of friendships) between students and the similarity between friends in terms of their smoking behaviour, gender, age, socio-economic status, and whether they were in the same tutor group. Results showed that selection effects (students choosing friends with the same smoking behaviour as themselves) were more important than peer influence effects (smoking students persuading non-smoking students to smoke), especially as the students got older. The influences of friends were also more important than individual influences of age, gender, socio-economic status and parental smoking. ${ }^{11}$

A focus on relational data means social network researchers can investigate three factors usually hidden from view in conventional social science: firstly, the effects of indirect ties - how your friends' friends, and their friends, may influence you without you ever having met them or even being aware 
of their existence ${ }^{12}$; secondly, how particular network structures may facilitate or hinder the spread of behaviour via social processes and norms, for example the decision by medical students to accept (or decline) seasonal influenza vaccination whilst at medical school ${ }^{13}$; and thirdly, how a person's position within a network (whether she or he is popular, powerful or peripheral) can affect how successful she or he is. ${ }^{14}$

\section{DESIGNING SOCIAL NETWORK STUDIES}

Just as there are myriad ways of collecting data on individuals, so there are many ways of collecting relational data, and the most appropriate method to use depends on the research questions and practical constraints. However, two major distinctions can be made between self-report and secondary source data.

\section{Self-report}

Surveys are an important method of collecting information on social contacts and processes ${ }^{15}$ and typically use either name generation or roster methods. The name generation method involves asking individuals to recall the names of people they have a particular type of relationship with, for example Burt et al. ${ }^{15}$ asked paediatric gastroenterologists to name up to five people they trust and up to five people they talk about quality improvement with. Vaughan, Sanders, Crossley et al. ${ }^{16}$ asked medical students to name up to 10 people important for their academic success. With the roster method, participants are given a list of names and asked to indicate which people they have a particular relationship with. For example, Woolf et al. ${ }^{17}$ asked all Year 2 medical students in one medical school to underline the names of their close friends on a list of everyone in their year. Name generation may provide incomplete network data because people can forget to nominate even close friends, ${ }^{18}$ but the roster method only works if the researcher knows which names to put on the list in advance. The methods used will determine the boundary of the network. Name generation can create networks in which little is known about the relationships between individuals other than that provided by participants, and although it is possible to ask participants to describe the relationships between their connections (e.g. students state who is friends with whom in their class), this is less reliable than selfreport. ${ }^{19}$ The roster method such as that used by Woolf $e$ al. ${ }^{17}$ and R. Isba (2015, unpublished data) creates a network with a clearly defined boundary (see Fig. 1; full colour version available online). However, this clear delineation can miss potentially important connections outside of that boundary. Laumann $e t a l .{ }^{20}$ provide further discussion of network boundaries.

The data presented in Fig. 1 were collected via a paper-based roster whereby each medical student at Lancaster Medical School in the academic year 2013-2014 was asked to indicate the strength of their relationship with every other medical student on the list. Year 1 and Year 2 students are densely connected within their years and fairly well connected to one another. By contrast, there are no direct ties between students in Year 1 and those in Years 3, 4 and 5, meaning information flowing from the higher years to Year 1 students would need to flow through Year 2 students. Year 5 students are the least connected group within year, and this may reflect the fact that they are more likely to be spread out widely on clinical placements. At the bottom of Fig. 1 there are two pairs of students who are not connected to the main part of the network structure and are therefore less likely to be influenced by, or influence, the majority of students. By contrast, the centrally-placed students that appear in the middle of the diagram could be considered brokers between students in Years 2, 3, 4 and 5.

\section{Secondary sources}

Social network data can be collected from books or other texts, ${ }^{21}$ journal article citations ${ }^{22}$ and 'digital trace' data ${ }^{23}$ such as mobile phone records ${ }^{24}$ and online social networks like Facebook. ${ }^{25}$ Secondary data can get around some of the problems that can arise with self-report data, such as low response rates and social desirability, although the validity of such data has been relatively unexamined. ${ }^{23}$ Disadvantages include difficulties obtaining data, ethical issues ${ }^{25}$ and data not being designed to answer research questions. The potentially huge amounts of data available can also pose difficulties for medical education researchers who may not have the training to manage and analyse 'big data', especially when there are the additional complications that network data pose.

\section{Ethical issues around data collection}

SNA research may raise ethical issues that are not often encountered elsewhere in experimental or survey research. Because the method focuses on relationships among people, each person is often asked to nominate specific, identifiable others to whom they are connected. The investigator may also 


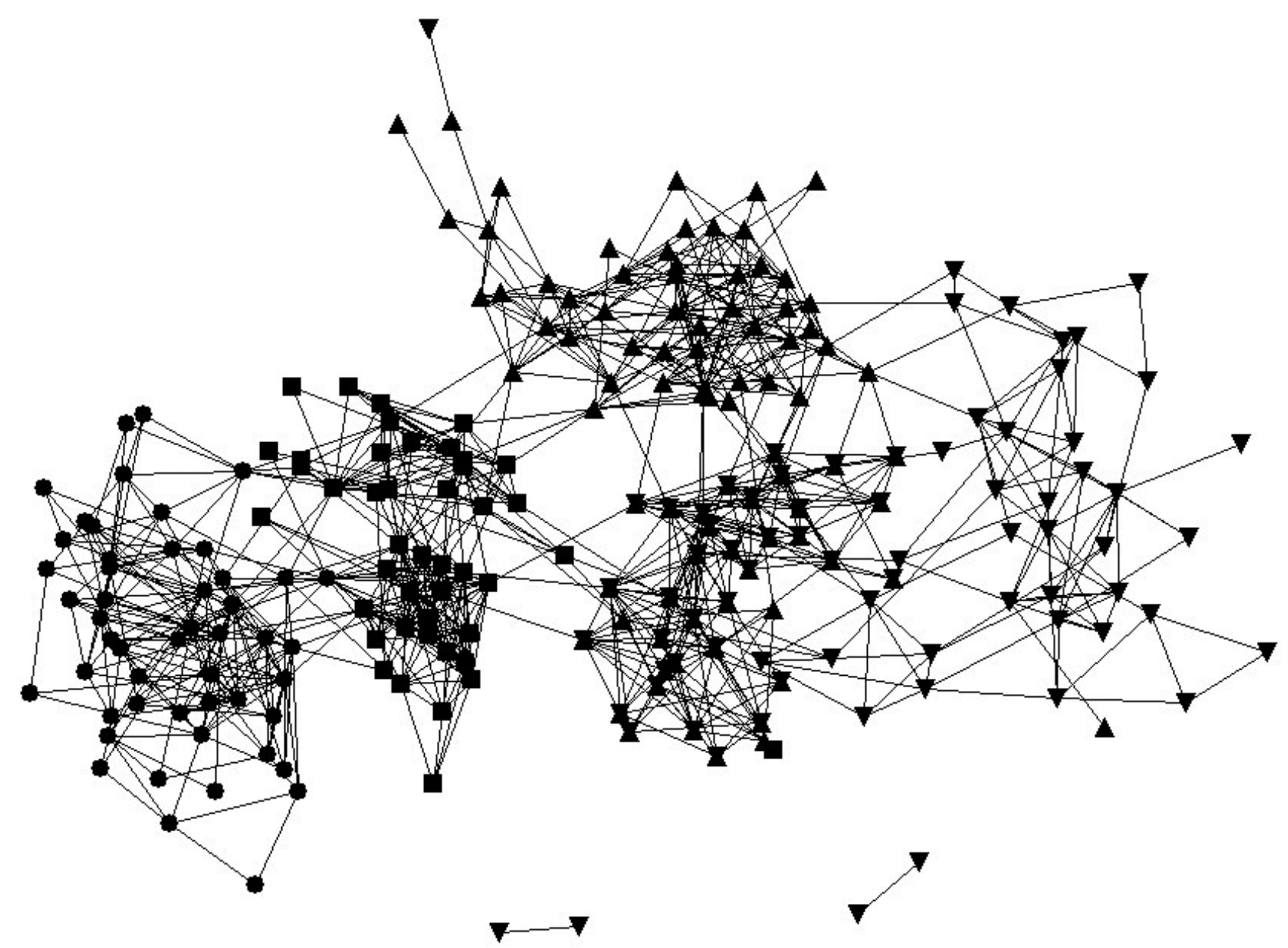

Figure 1 Friendships between Lancaster medical students during the academic year 2013-2014 with isolates removed $(n=206)$. Friendship ties were symmetrised (at the value of the lower tie strength reported by AB or BA). A tie between two individuals is present if they indicated that they knew the other person and saw or spoke to them three or more times a week, or had a close personal relationship with them. Isolates (those with no ties) are deleted. The different shapes represent students in each of the 5 years of the course: circles, Year 1; squares, Year 2; up triangles, Year 3; hourglasses, Year 4; down triangles, Year 5. Unpublished data, Rachel Isba (2015). Full colour version available online.

sometimes ask the respondent to characterise the attributes of the others to whom they are connected. Unless everyone identified in a network study is directly contactable and gives their consent to inclusion, potentially identifiable data about some subjects may be included without their direct consent. In the majority of cases, careful research oversight combined with sensitive data collection and analysis will assure the risks are minimised. However, in work that focuses, for example, on risky behaviour or attitudes, great care must be taken to protect the privacy of research subjects.

\section{STATISTICAL ANALYSIS OF NETWORK DATA}

Relational data, although powerful, are potentially problematic to analyse as they are statistically non- independent and thus violate assumptions of conventional statistical tests. This problem can be overcome by using permutation testing, in which the results obtained are compared against results obtained from 10000 or so random or quasi-random permutations of the data. Until fairly recently, permutation testing was too computationally intensive for researchers to perform on their ordinary desktop or laptop computers. However, advances in processing power now mean that most researchers can easily handle data from networks of a few hundred nodes, and the ability of researchers to analyse network data with millions of nodes from online social networking sites such as Facebook and Twitter is becoming easier. ${ }^{26}$ These technical advances have aided the development of user-friendly social network analysis programmes (many of which, such as Pajek ${ }^{27}$ and UCINET, ${ }^{28}$ are available for free or for 
a nominal fee) and have also helped move the field on theoretically, all of which has started to bring social network analysis into the mainstream. ${ }^{2}$ That being said, the fact that social network analysis is still a relatively new and cross-disciplinary approach means that data collection and analysis methods are still relatively specialised and there is comparatively little in the way of training in understanding conceptually and statistically complex data. Some researchers have argued that this, in turn, leads to significant errors. ${ }^{29}$

APPLICATIONS OF SOCIAL NETWORK ANALYSIS

Social network analysis is an interdisciplinary field. For mathematicians and statisticians it presents interesting challenges for modelling what are often extremely complex systems. For sociologists and economists it provides a new way of understanding how large social systems work. For organisation and management scientists it gives insight into how teams work within organisations. For psychologists, medics and educationalists, it can shed light on how individual outcomes are influenced by social processes. All of these are relevant to medical education. Some of the most common types of question addressed in social network studies and the underlying network processes being investigated are described below, followed by ideas about how these types of questions have, or might be, applied to medical education.

\section{Team working}

Creating and supporting effective teams is clearly of great importance in many areas and has been heavily researched. In SNA, questions are typically about how patterns of relationships within and between team members can affect information and resource exchange or influence performance. Effective teams tend to have many within-team interactions and have non-hierarchical structures in which everyone interacts with everyone else. ${ }^{30,31}$ However, measures of effectiveness differ hugely between studies; for example, a review of teamwork in health care provision included outcomes as varied as burnout at the level of the individual professional and financial profit at the level of the hospital. ${ }^{32}$ Medical education research could use social network analysis methods to explore team-working in an undergraduate setting, for example looking at how social relationships within teaching groups develop and how they are influenced by the practices of the medical school or medical teachers, as well as by the characteristics of the individual medical students. They could go on to explore how these social structures relate to educational outcomes for all team members or for particular individuals, for example those with low prior educational attainment.

\section{Individual success and network position}

A large strand of social network analysis has addressed questions of how an individual's position within social networks can affect their success, key theories being Mark Granovetter's theory of weak ties, ${ }^{33}$ Ron Burt's structural hole theory ${ }^{14,34}$ and Robert Putnam's social capital theory. ${ }^{35}$ Social ties require investment of time and resources, which limits the number of strong ties a person can have. Strong ties tend to be within close-knit communities and provide what Putnam termed bonding capital in the form of emotional and practical support. Ties with people in other networks outside those closeknit communities tend to be weaker. However, Granovetter theorised that weak ties are in fact the ones that provide resources and lead to success, ${ }^{33,36}$ providing what Putnam calls bridging capital. Similarly, Burt refers to the individuals who connect otherwise unconnected groups as brokers who fill structural holes in networks and are therefore particularly powerful and creative. ${ }^{14}$

Understanding the causes and effects of network position in medical education is relevant in a context in which trainees often move around departments, hospitals, regions and even countries over the course of their training, where there is significant competition for jobs and frequent formative and summative assessments. Despite this, there is a relative paucity of research on network position in health care. ${ }^{37}$ Medical education researchers could examine how the depth and breadth of medical students' or medical trainees' professional networks relate to successful outcomes in training, for example obtaining a job or passing an examination.

\section{Spread of behaviour and peer influence}

The spread of communicable diseases such as influenza and human immunodeficiency virus (HIV) through networks is much studied in public health. Similarly, SNA has been used to map and predict the spread of information and behaviours through groups of people, the most famous probably being Coleman, Katz and Menzel's ${ }^{38}$ diffusion of innovation study, which found that doctors who were well respected by their colleagues were faster to prescribe a new drug. Christakis and Fowler have used 
the Framingham Heart Study data to show that psychological and physical phenomena such as happiness and obesity can spread through social networks. ${ }^{12,39,40}$ The spread of information through social networks is relevant to understanding social learning in medicine. Medical students' and doctors' social networks are continually developing and potentially influencing their acquisition of skills and knowledge. ${ }^{17}$ Organisations can have an impact on students' networks: being randomly allocated to the same teaching group facilitates friendships ${ }^{17}$ and a study of primary care doctors found they tend to seek advice from colleagues who are physically easier to reach (e.g. who work in the same clinic). ${ }^{41}$ Tasselli ${ }^{42}$ provides a review of research into the social networks of health care professionals. In students, the social network within a medical school (and the multiple different networks that exist within or overlap with it) is probably best conceptualised as part of the hidden curriculum in that it is a pervasive, highly influential, yet unintended part of the medical school experience, and one that is only starting to be explored using social network methods. ${ }^{43}$ The ways in which information and resources spread through networks are influenced partly by network structures, but also by the behaviours of individuals who occupy particular positions of power and influence within networks and can therefore direct flow. ${ }^{44}$ Near peers are an important influence on students' behaviours ${ }^{45}$ although the influence of senior students should not be underestimated. An understanding of how network structures and particular individuals in powerful positions influence behaviours can help researchers design network interventions to halt the spread of undesirable behaviours and promote the spread of desirable behaviours.

To date there are relatively few social network-based interventions in health care ${ }^{46}$ and we could find none in medical education. In education more generally, Paluck and Shepherd ${ }^{47}$ recruited high school students who were either well known to the whole student body (had weak influence over a large group) or clique-leaders (had strong influence on a small group) to take part in an anti-bullying intervention. Following the intervention, students who were socially close to the intervention students had better attitudes and behaviours towards bullying compared with those who were socially close to control pupils, and the well-known students differed from clique-leaders in the effects they had on their peers' behaviour. Influences on professional or unprofessional behaviour in medical students or doctors could be explored using similar methods. If, for example, students with poor professional attitudes and behaviours occupy influential positions with the medical student social network or if there is evidence that students with similar levels of professionalism cluster together, this could influence ways of remediating students, which might lead to improved professionalism in professional practice and ultimately improve patient care.

\section{Social cohesion and power}

A common feature of social networks is that people who are similar, especially in age, sex, ethnicity and educational level, are more likely to be closely linked and therefore tend to cluster together in networks. This is known as homophily and it can result from several possible mechanisms, including preference (e.g. university graduates preferring friends who are also university graduates), peer influence (e.g. university graduates encouraging their nongraduate friends to go to university) or confounding (e.g. a key time for making friends is university and proximity facilitates friendship). One strand of social network analysis is concerned with understanding and changing the power structures within societies that are based on homophilous tendencies, and which constrain opportunities for people who are different from those in power, such as ethnic minorities, women or people from lower socio-economic groups. ${ }^{48}$ Woolf et al. ${ }^{17}$ and Vaughan et al. ${ }^{16}$ found that medical student networks are influenced by ethnicity, with implications for learning. Creating interventions to address inequalities requires an understanding of the causal mechanisms underpinning homophily and its role in the maintenance of power structures, and here longitudinal studies and studies in which people are randomly allocated to social situations such as tutorial groups are key.

Social network analysis has also been used to study the development of social and political movements, such as the civil rights and universal suffrage movements of the 20th century, often in conjunction with qualitative data, for example from letters between key actors in the movements. ${ }^{49,50}$ Similar methods could be used to examine how medical education policies are shaped by relationships between key players in the field.

\section{CONCLUSIONS}

Social network analysis (SNA) is a research method gaining popularity in mainstream social science and the field of medical education thanks to advances in 
computing that make it easier than ever to analyse network data. A small but growing body of evidence in medical education research suggests that SNA may help elucidate some of the previously unknown influences upon medical students and doctors, including the spread of attitudes and behaviours and differences in attainment between social groups. This in turn can lead to interventions to optimise positive effects and minimise those that may negatively impact on medics and patients. Social network analysis is therefore an important tool in the development and delivery of undergraduate and postgraduate medical education.

Contributors: All authors contributed to the concept and planning of the entire paper. All authors extensively edited each portion of the paper and contributed to writing the overview and conclusion sections. All authors gave final approval of the version to be published.

Acknowledgements: RI would like to thank her students for help with the work that resulted in Fig. 1, especially Joe McAleer, Rachel Howarth, Joe Heath and Rhiannon Edge.

Funding: RI and KW received the inaugural Medical Education Travelling Fellowship that enabled them to travel to California and make the initial connections with RH that have resulted in this paper.

Conflicts of interest: All authors declare they have no conflicts of interest.

Ethical approval: Ethical approval was obtained for the study which resulted in the data that appear in Fig. 1.

\section{REFERENCES}

1 Baumeister RF, Leary MR. The need to belong: desire for interpersonal attachments as a fundamental human motivation. Psychol Bull 1995;117 (3):497-529.

2 Borgatti SPE, Everett MG, Johnson JC. Analyzing Social Networks. London, UK: Sage Publications 2013.

3 Scott J. Social network analysis. Sociology 1988;22 (1):109-27.

4 Jackson MO. Social and Economic Networks. Princeton, NJ: Princeton University Press 2008.

5 Borgatti SP, Mehra A, Brass DJ, Labianca G. Network analysis in the social sciences. Science 2009;323 (5916):892-5.

6 Eggens L, Werf MPC, Bosker RJ. The influence of personal networks and social support on study attainment of students in university education. High Educ 2007;55 (5):553-73.

7 Liebowitz J. Linking social network analysis with the analytic hierarchy process for knowledge mapping in organizations. J Knowl Manag 2005;9 (1):76-86.

8 Lindelauf R, Borm P, Hamers H. The influence of secrecy on the communication structure of covert networks. Soc Netw 2009;31 (2):126-37.
9 Luke DA, Harris JK. Network analysis in public health: history, methods, and applications. Annu Rev Public Health 2007;28 (1):69-93.

10 Moreno JL. Who shall survive? A new approach to the problem of human interrelations: Nervous and Mental Disease Publishing Co, 1934. http:// www.asgpp.org/docs/wss/wss.html. [Accessed 9 June 2016].

11 Mercken L, Steglich C, Sinclair P, Holliday J, Moore L. A longitudinal social network analysis of peer influence, peer selection, and smoking behavior among adolescents in British schools. Health Psychol 2012;31 (4):450-9.

12 Christakis NA, Fowler JH. Social contagion theory: examining dynamic social networks and human behavior. Stat Med 2013;32 (4):556-77.

13 Edge R, Heath J, Rowlingson B, Keegan TJ, Isba R. Seasonal influenza vaccination amongst medical students: a social network analysis based on a cross-sectional study. PLoS ONE 2015;10 (10): e0140085.

14 Burt RS. Structural holes and good ideas. Am J Sociol 2004;110 (2):349-99.

15 Burt RS, Meltzer DO, Seid M et al. What's in a name generator? Choosing the right name generators for social network surveys in healthcare quality and safety research. BMJ Qual Saf 2012;21 (12):992-1000.

16 Vaughan S, Sanders T, Crossley N, O’Neill P, Wass V. Bridging the gap: the roles of social capital and ethnicity in medical student achievement. Med Educ 2015;49 (1):114-23.

17 Woolf K, Potts HWW, Patel S, McManus IC. The hidden medical school: a longitudinal study of how social networks form, and how they relate to academic performance. Med Teach 2012;34 (7):57786.

18 Brewer DD. Forgetting in the recall-based elicitation of personal and social networks. Soc Netw 2000;22 (1):29-43.

19 Neal JW, Neal ZP, Cappella E. Seeing and being seen: predictors of accurate perceptions about classmates' relationships. Soc Netw 2016;44:1-8.

20 Laumann EO, Marsden PV, Prensky D. The boundary specification problem in network analysis. In: Burt RS, Minor MJ, eds. Applied Network Analysis: A Methodological Introduction. Beverley Hills, CA: Sage 1983;18-34.

21 Stevenson R, Crossley N. Change in covert social movement networks: the 'inner circle' of the provisional Irish Republican Army. Soc Mov Stud 2014;13 (1):70-91.

22 Goffman C. And what is your erdos number? Am Math Mon 1969;76 (7):791.

23 Howison J, Wiggins A, Crowston K. Validity issues in the use of social network analysis with digital trace data. J Assoc Inf Syst 2011;12 (12):767-97.

24 Eagle N, Pentland A, Lazer D. Inferring friendship network structure by using mobile phone data. Proc Natl Acad Sci USA 2009;106 (36):15274-8. 
25 Stopczynski A, Sekara V, Sapiezynski P, Cuttone A, Madsen MM, Larsen JE, Lehmann S. Measuring largescale social networks with high resolution. PLOS ONE 2014;9 (4):e95978.

26 Coviello L, Sohn Y, Kramer ADI, Marlow C, Franceschetti M, Christakis NA, Fowler JH. Detecting emotional contagion in massive social networks. PLoS ONE 2014;9 (3):e90315.

27 de Nooy W, Mrvar A, Batagelj V. Exploratory Social Network Analysis With Pajek: Revised and Expanded, 2nd edn. New York, NY: Cambridge University Press 2011.

28 Borgatti SP, Everett MG, Freeman LC. Ucinet for Windows: Software for Social Network Analysis. Harvard, MA: Analytic Technologies 2002.

29 Lyons R. The spread of evidence-poor medicine via flawed social-network analysis. Statistics, Politics, and Policy 2011;2 (1): Article 2.

30 Balkundi P, Harrison DA. Ties, leaders, and time in teams: strong inference about network structure's effects on team viability and performance. Acad Manag J 2006;49 (1):49-68.

31 Grund TU. Network structure and team performance: the case of English premier league soccer teams. Social Networks 2012;34:682-90.

32 Cunningham FC, Ranmuthugala G, Plumb J, Georgiou A, Westbrook JI, Braithwaite J. Health professional networks as a vector for improving healthcare quality and safety: a systematic review. BMJ Qual Saf 2012;21 (3):239-49.

33 Granovetter MS. The strength of weak ties. Am J Sociol 1973;78 (6):1360-80.

34 Burt R. Structural Holes: The Social Structure of Competition. Cambridge: Harvard 1992.

35 Putnam RD. Bowling Alone. New York, NY: Simon \& Schuster 2000.

36 Granovetter MS. The strength of weak ties: a network theory revisited. Sociol Theory 1983;1:32.

37 Long JC, Cunningham FC, Braithwaite J. Bridges, brokers and boundary spanners in collaborative networks: a systematic review. BMC Health Serv Res 2013;13 (1):1-13.

38 Coleman J, Katz E, Menzel H. The diffusion of an innovation among physicians. Sociometry 1957;20 (4):253-70.

39 Christakis NA, Fowler JH. The spread of obesity in a large social network over 32 years. $N$ Engl J Med 2007;357 (4):370-9.

40 Fowler JH, Christakis NA. Dynamic spread of happiness in a large social network: longitudinal analysis over 20 years in the Framingham Heart Study. BMJ 2008;337:a2338.

41 Keating NL, Ayanian JZ, Cleary PD, Marsden PV. Factors affecting influential discussions among physicians: a social network analysis of a primary care practice. J Gen Intern Med 2007;22 (6):794-8.

42 Tasselli S. Social networks of professionals in health care organizations: a review. Med Care Res Rev 2014;71 (6):619-60.

43 Hafferty FW, Castellani B, Hafferty PK, Pawlina W. Anatomy and histology as socially networked learning environments: some preliminary findings. Acad Med 2013;88 (9):1315-23.

44 Friedkin NE, Johnsen EC. Social positions in influence networks. Soc Netw 1997;19 (3):209-22.

45 McAleer J. What are the Student Interactions Within the Social Network of a Medical School?: Lancaster University 2012.

46 Chambers D, Wilson P, Thompson C, Harden M. Social network analysis in healthcare settings: a systematic scoping review. PLoS ONE 2012;7 (8): e41911.

47 Paluck EL, Shepherd H. The salience of social referents: a field experiment on collective norms and harassment behavior in a school social network. J Pers Soc Psychol 2012;103 (6):899-915.

48 Ibarra H. Race, opportunity, and diversity of social circles in managerial networks. Acad Manag J 1995;38 (3):673-703.

49 Saunders C. Using social network analysis to explore social movements: a relational approach. Soc Mov Stud 2007;6 (3):227-43.

50 Edwards G. Mixed Methods Approaches to Social Network Analysis. UK: ESRC National Centre for Research Methods 2010.

\section{SUPPORTING INFORMATION}

Additional Supporting Information may be found in the online version of this article:

Figure S1 Friendships between Lancaster medical students during the academic year 2013-14 with isolates removed $(n=206)$.

Received 4 March 2016; editorial comments to author 25 April 2016, 27 June 2016; accepted for publication 1 July 2016 